\title{
THE STRUCTURAL FACE OF COMPETITION, COOPERATION AND COOPETITION INSIDE BUSINESS NETWORKS
}

The structural view on networking as well as the application of the social network analysis in the area of inter-organizational network theory have become more and more popular recently. However, little attention in the previous literature has been paid to the quantitative and structural exploration of networking processes which occur inside i.e. collaboration, competition and coopetition.

Drawing on a resource based view and social network analysis, the article presents the usefulness of structural analysis for networking improvement. This research contributes to the network theory by presenting the possible ways of using structural measurements for networking strategy adoption and by applying structural measurements to the seldom explored area of coopetition processes inside networks. Furthermore, some managerial implications as well as some limitations of the presented methods are shown at the end of the paper.

Keywords: structural analysis, networking, social network analysis, cooperation, collaboration, coopetition, competition

DOI: 10.15611 aoe.2015.1.05

\section{INTRODUCTION}

The dramatic increase of the cooperation and networking processes in recent years (Hoffmann et al., 2010) has directed the attention of researchers to networking. The growing popularity of networking arises from several megatrends. Among the most important pro-networking factors are: the shortening life cycles of markets, sectors, technologies and products; the growing interdisciplinary character of most technologies and the increasing financial and time requirements of R\&D activities (Santamaria and Surroca, 2011). Based on the above, networking appears as a source of above-average profits and competitive advantage (Dyer and Singh, 1998). In general, a fast-changing environment calls for inter-organizational collaboration (Amankwah-Amoah and Debrah, 2011) or even enforces such collaboration (Doz and Hamel, 2006). Under consideration there are collaborative networks which are an excellent environment for long-term and beneficial cooperation and (or) coopetition processes. Furthermore, more and more companies participate in more than one inter-organizational network (Gulati, 1999).

*Management Theory Department, University of Economics in Katowice 
It seems that scholars agree on the definition and conceptualization of a network as well as of the network paradigm. But now they have to face methodological challenges in investigating the networking processes which occur inside i.e. collaboration, competition and coopetition. The main question is how to analyze and monitor these inter-organizational and intranetwork processes. Structural analysis, a research method incorporated from sociology, may be considered as one of the possible solutions. Therefore the main objective of the paper is the presentation of the usefulness of structural analysis for networking strategy adoption and improvement. The application of structural analysis methodology allows us to identify inter alia the network integrators, sources of knowledge, isolated and peripheral partners, the most dangerous competitors, and the most important channels for knowledge transfer.

Drawing on the literature in sociology and strategic management, this paper sheds some new light on the usefulness of structural analysis for networking strategy adoption and improvement. It deals with the central issues in network management, namely the approaches to the investigation and the evaluation of networks' activity and networking strategies. Past attempts to apply social network analysis in the field of strategic management and networking processes were focused towards testing the significance of various endogenous and exogenous structural measurements but (mainly) were conducted at one level of analysis only. Therefore this paper attempts to present the usefulness of a complete and comprehensive set of structural measures at the micro, meso and macro levels for monitoring and improving networking strategies and processes.

\section{Theoretical background}

The world in the 21st century resembles a multidimensional, multi-criteria network comprising multiple network nodes located on different planes and in different areas. We are talking here about social networks (e.g. built using Facebook, LinkedIn, or Goldenline), inter-organizational networks (e.g. ubiquitous clusters and franchise systems) and IT networks (e.g. Internet). Because networks are omnipresent, today's economy is referred to as a network economy (Shuman et al., 2001). In management sciences, interest in network-based collaboration is at its peak, and networks are "euphorically discussed" (Park 1996, p. 805) in the latest management literature.

From the perspective of Resource Based View, the dynamic popularization of inter-organizational networks could be determined by the 
perception that networks are strategic assets generating a longitudinal competitive advantage (Czakon, 2011). In general, the Resource Based View theory assumes that both economic rent and competitive advantage or even the survival of a company depends of the strategic resources (in terms of Barney 1991) it owns, it controls or to which it has access (Tremblay et al., 2003; Lakshman 2012). However, in today's business world more and more companies suffer from resource gaps (Romanowska 2002). The growing resource deficiencies turn companies' attention to establishment of interorganizational relationships and becoming actors of inter-organizational networks (Teng 2006, Czakon 2012) as cooperative relationships and networks are perceived as invaluable source of missing competencies and strategic resources (Jarillo 1988; Gulati 1999; Gulati 2007) which the company would not otherwise be able to independently produce (Powell et al., 1996, Teng 2006, Nieto and Santamaría, 2010). Furthermore, the interorganizational networks in themselves are perceived as a source of substantial value added providing and leveraging key competencies (Hamel and Prahalad, 1990). However, to gain access to resources and competencies available inside the network held by other actors (Roininenand Westerberg, 2008) the organizations ought to be able to develop and utilize interorganizational relationships (i.e. they should have network capability, Walter et al., 2006, p. 541). The ever-increasing popularity of networks have caused supporters of the resource dependence theory to acknowledge other than traditional (i.e. tangible assets, financial resources, human resources and information resources) resources as fully-fledged resources crucial for organizational success. They recognize as such relational (Dyer and Singh, 1998) and networks' resources (Gulati 1999; Gulati 2007), which benefit actors of inter-organizational networks (Gulati 1998). Organizations within a network are interlinked by mutual relationships which are capable of generating a competitive advantage referred to as relational rent (Dyer and Singh, 1998, Lorenzoni and Lipparini, 1999).

A network is built by at least three relatively independent and selfcontained companies engaged in long-term, non-incidental relationships aimed at achieving common goals (Czakon 2012). Hence, a network is a form of organized activity taking the form of a complex system of nodes connected by different types of relationships (Gulati 2007). The number and configuration of these two network components (i.e. ties and nodes) determines its structure (Wasserman and Faust, 1997). Nodes (also labelled as actors, vertices, or partners) are different organizations making up the network. Nodes are usually diversified in terms of size, maturity, type of 
business entity and even business profile. Actors of the network are both commercial enterprises as well as non-commercial organizations e.g. universities, $R \& D$ centres, financial institutions. Network nodes are also diversified in terms of the location they reside in (centre or periphery) within the network, the roles they play and their functions, as is particularly evident in the case of centralized and asymmetric networks. The other component of networks is a set of inter-organizational ties (also labelled as relationships, links, or edges). Nodes forming the network are interconnected by special relationships in the form of long-term inter-organizational interactions which facilitate the exchange of information, assets, energy and human resources, provided both partners are proactive and mutually involved (Czakon 2012) ${ }^{1}$. Ties keeping the network together are unsolicited (Van de Ven 1976) and established to achieve common objectives, however, they not always they improve competitive advantage (Jarillo 1988). The collocation and character of the ties is determined predominantly by the number of nodes (size of the network) and strength of the nodes' involvement (density of the network).The structure of the network not only determines its shape, but also affects its activity (Gnyawali and Madhavan, 2001). In the case of interorganizational networks, the number of nodes and ties as well as their location relative to each other is important for communication processes, transfer of information, technology, knowledge and ideas, flow of goods and capital within the network (Walker et al., 1997; Gargiulo and Benassi, 2000). In other words, it should be noted that the deliberate shaping of the relationships among organizations within the network is one of the possible ways for leveraging the benefits gained from networking (Peng and Bourne, 2009).

The network structure also affects how easy it is to control, i.e. the more autonomous actors (nodes) it incorporates, the harder it is to control. Existing research also proves that the structure of the network affects its nodes' behaviour (Granovetter 1973), the diffusion and transfer of information and innovation (Abrahamson and Rosenkopf, 1997), determines the available opportunities for its actors to access resources stored within the network. Therefore the considerations about structural analysis and measurements have aroused more debate in the field of management in recent years (Gnyawali and Madhavan, 2001; Müller-Prothmann 2006; de Laat et al., 2007; Ter Wal and Boschma, 2009; Czakon 2012). Researchers are trying to find the appropriate approaches, methods and techniques for

\footnotetext{
${ }^{1}$ More details about structural view on inter-organizational networks: Klimas, 2013.
} 
networking analysis and improvement. Some of them are crossing boundaries of management theories and are trying to use research methods derived from different academic disciplines. The application of Social Network Analysis (SNA, also called structural analysis (Reffay and Chanie, 2003) or network analysis (Borgatti et al., 2009)) is an excellent example of such a methodological transfer. Prior literature indicates that in the area of strategic management the structural measures incorporated from SNA may be applied to improve project management (Mead 2001), human relationship management (Cross et al., 2001); social capital management (Boutilie 2007) and/or knowledge management (Liebeskind et al., 1996; Boschma and Ter Wal, 2007).

\section{The essence of structural analysis}

The increasing popularity of social network analysis has been observed in sociology for the past 30 years. In management sciences on the other hand, the last decade was the period when its recognition rose significantly (Mead 2001). Structural analysis is a research methodology aimed at identifying patterns of relationships based on how nodes are connected with each other. It is applied to describe and understand the patterns of interaction among nodes within the network (Scott 2000; Wasserman and Faust, 1997). Structural analysis provides a lot of information important for management regarding internal and external relationships, network edges, changes within the networks, distribution of knowledge as well as formal and informal leadership (Tichy et al., 1979). Furthermore, network analysis is useful for describing actors of the network and identifying, determining the direction and intensity of tangible and intangible inter-organizational flows (Rowley et al., 2000). The wide spectrum of applicable measures of structural analysis means it could be employed to a plethora of management areas specific for inter-organizational networks (Klimas 2013).

Firstly, network analysis can serve as a tool for stabilising the network and a method to gather information about companies useful for management purposes: the most involved in the network, those isolated from partners and transfers of resources within the network, the key for the integrity of the network whose separation from it could cause partial and full fragmentation, and nodes creating different types of subgroups (sub-networks) which could migrate away from the network.

Secondly, structural analysis is a methodology of researching and assessing processes of inter-organizational learning, transferring and diffusing knowledge (Cross et al., 2001). It can be used to improve 
knowledge management by applying centralization, centrality, density and sub-groups (Müller-Prothmann 2006). These measures allow assessing the structure and probable directions of evolution (intentional and incidental) of knowledge flows within a network (Ter Wal and Boschma, 2009); identifying external sources of knowledge worthy of establishing new or tightening existing relationships thereby increasing access to knowledge; increasing its heterogeneity and optimising channels facilitating knowledge flow (Cross et al., 2001).

Thirdly, in the case of innovation networks it can help to improve the processes of orchestrating (in terms of Dhanaraj and Parkhe, 2006) all of its components. First, the identification of knowledge sources improves managing the mobility of knowledge. Second, recognising information brokers (structural gaps) enables counteracting the undue appropriation of value and innovation. Third, assessing the cohesion of the network and identifying potential cut-off points allows to better manage the stability of the network (Jędrysik 2010).

Summing up, when we take into account that network structure may have a positive and negative influence on network activity and networking performance (Rowley et. al., 2000), it becomes clear that the evaluation and continuous monitoring of various structural parameters are important for managerial processes.

Structural analysis is a user-friendly tool for networks mapping, providing additional useful analytical data about the activity and relationships inside the network (de Laat et al., 2007) ${ }^{2}$. This is based on the careful investigation and exploration of relational data gathered in matrices of relationships. Relational matrices may be built using the characteristics of the nodes examined (two-mode, rectangular, case-by-affiliation matrix) or the ties among them (one-mode, square, case-by-case matrix) (Marin and Wellman, 2010). In the following step the data from relational matrices is transformed into special graphs and analyzed simultaneously at three levels of exploration (Wassermann and Faust 1997; Scott 2000; Prell ${ }^{2012)}$. First, at the node level we are able to use such measurements as degree (also in degree and out degree in the case of directed networks), closeness centrality, betweenness centrality, structural holes and eigenvector. They are useful to (1) assess the power and prestige of particular nodes, (2) recognize potential partners and competitors and (3) find out which relationships should be monitored because of the high probability of knowledge leakage. Second, the evaluation of the network consistency and its stability which may be

\footnotetext{
${ }^{2}$ More details about application of structural analysis in management research: Klimas, 2013
} 
carried out using: clique, $\mathrm{n}$-cliques, $\mathrm{k}$-cores and $\mathrm{m}$-slices (parameters at the sub-group level). Third, at the network level we might consider quantity of nodes, length of the network diameter, or the level of network density, cohesion and connectedness. These measures are useful for managing the network and ensuring the whole network stability. Moreover, the holistic assessment of intra-network flows and processes may be supported by information about the core and periphery inside the network and the structural equivalence between nodes (6 et al., 2006).

It should be stated that structural measures may be applied to investigate the network of ties created around a particular actor (egocentric network) or network of all ties on the market (complete/full network). Moreover, we are able to apply the network structure to investigate both formal and informal networks. Formal network analysis provides information about the closest rivals, coopetitors and partners and also about the most significant knowledge sources within the industry. Furthermore, informal network analysis provides information about unofficial communication channels, informal leaders and trustworthy partners (Klimas 2013).

Prior research indicates that structural analysis has a wide range of applications in the field of inter-organizational networks and that different structural parameters play a crucial role in long-term and effective collaboration. For example (Peng and Bourne,2009) used connectedness, network size, type of relationships and network scope to investigate the ability of networks to maintain the balance between the forces for cooperation and for competition. On the other hand, Gnyawali and Madhavan (2001) suggest that centrality, structural autonomy and structural equivalence influence action likelihood and response likelihood during networking. Moreover, in their opinion, these relationships are moderated by the density of the whole network. Structural analysis may also be helpful in modelling and monitoring the flow of information, knowledge and other resources that are shared and exchanged among nodes (Ter Wal and Boschma, 2009). Furthermore, structural measurements may be used for network structure management and the maintenance of an appropriate location within the network. This results from the fact that structural measures have an impact on the degree of knowledge and network resources accessibility, as well as on innovation performance (Kim and Lee, 2010) and creativity (Ohly et al., 2010). Additionally, Tsai (2002) showed that centralization and tie strength (assessed based on social interaction and interunit competition) stimulate inter-organizational knowledge sharing among network members. All of the above evidence indicates that structural analysis is a useful tool for improving networking processes at many levels. 
However, the usefulness of structural measurements in the field of networking processes has some limitations. Structural analysis is applied to investigate relationships and their patterns within networks of nodes, therefore it is useful when we consider more than two organizations. In the case of bilateral relations (dyadic ties), structural measurements will not provide significant information and have cognitive value. Moreover, it has a static character and takes a picture of networking processes at a particular point in time while they are dynamic in nature.

\section{Structural analysis of networking processes- evidence from a case study}

Inter-organizational dynamics may take the form of coexistence, cooperation, competition and coopetition (Bengtsson and Kock, 1999). All of these dynamics appear parallel and simultaneously but also asymmetrically in the business space and inside inter-organizational networks. It should be noted that structural analysis is useful in the case of collaboration, competition and coopetition only. Its cognitive value is limited for coexistence investigation due to the fact that it can only be used for the identification of isolated nodes. In general, the phenomenon of coexistence remains outside managerial considerations, especially if we take into account that it is assumed that only nodes linked by (at least one) ties co-create interorganizational networks (Klimas 2014).

Analysis of the competition inside the network. A competition network consists of market (direct and indirect) competitors and all the active, competitive ties among them. Competitive ties represent an overlapping domain of business activity. Depending on the level of detail, they may represent: (1) the same code of business activity (e.g. according to NACE codes), (2) the number of the same markets of activity or (3) the number of the same provided products and services. The main benefit from competition analysis is providing information about the closest rivals. In the case of networking information about competitive ties and their structure, it is important to monitor them thus ensuring protection against leakages of tacit and hot knowledge.

Analysis of the collaboration inside the network. A cooperation network consists of cooperation partners and the links among them. These ties reflect existing cooperation processes, understood as a longitudinal, purposeful and joint activity (Czakon 2012). Each jointly implemented project or joint participation in an inter-organizational network results in a cooperative tie. The analysis of a cooperation network gives an insight into the most open and the most important research-intensive organizations with access to the 
latest knowledge. It is important to recognize such organizations as they are creators of the future and give access to the key success factors which will be the base for competitive advantage in future.

Analysis of the coopetition inside the network. Coopetition refers to simultaneous cooperation and competition (Bengtsson and Knock, 2000). In the case of networks, coopetition is a kind of inter-organizational relationship mix (Osarenkhoe 2010) and a coopetitive network is formed by overlapping cooperative and competitive ties. Therefore it is created as the intersection of competition and collaboration networks.

In first two out of these three abovementioned types of networks it is possible to assess the tie strength. The higher the number of overlapping business areas and (or) jointly realized activities, the higher the tie strength.

The presentation of the usefulness of structural analysis is based on the empirical case of the Polish aviation network - the Aviation Valley Association (AVA). The data collection process focused on the Aviation Valley followed the rigour necessary for case studies. The literature suggests (Eisenhardt and Graebner, 2007), that case study data need to be triangulated or compared from many different sources in order to reduce single source bias and ensure credibility. In order to meet the above requirements several primary sources of data were used including semi-structured interviews, questionnaire surveys and observation. The timeframe of data gathering covers the time period between June and July 2012.

The Aviation Valley Association $\left(\mathrm{AVA}^{3}\right)$ was established in 2003 in Rzeszów. The AVA is the biggest aviation cluster in Poland and the third largest aviation cluster in Europe (after Hamburg and Toulouse). As of 2012 there were more than 90 members, 23.000 employees, and the turnover exceeded 1 billion euros. The AVA covers more than $90 \%$ of the Polish aviation industry and most of the Polish aviation companies are its members. It should be noted that the network of ties within the AVA reflects the general structure of the whole industry. The boundaries of the investigated network are set by membership in the AVA, therefore the analysis was carried out on the complete network. The investigation of the network structure was based on the analysis of 93 nodes and active ties among the edges. In general, to analyze the structural side of the networking processes within the AVA, three separate networks of ties have been created: competition, cooperation and coopetition (Figure 1).

\footnotetext{
3 Based on secondary data collected from the AVA's website, reports and documents provided by the AVA's President. More details about Aviation Valley Association: Klimas 2014
} 
$\square$ Isolated competitors
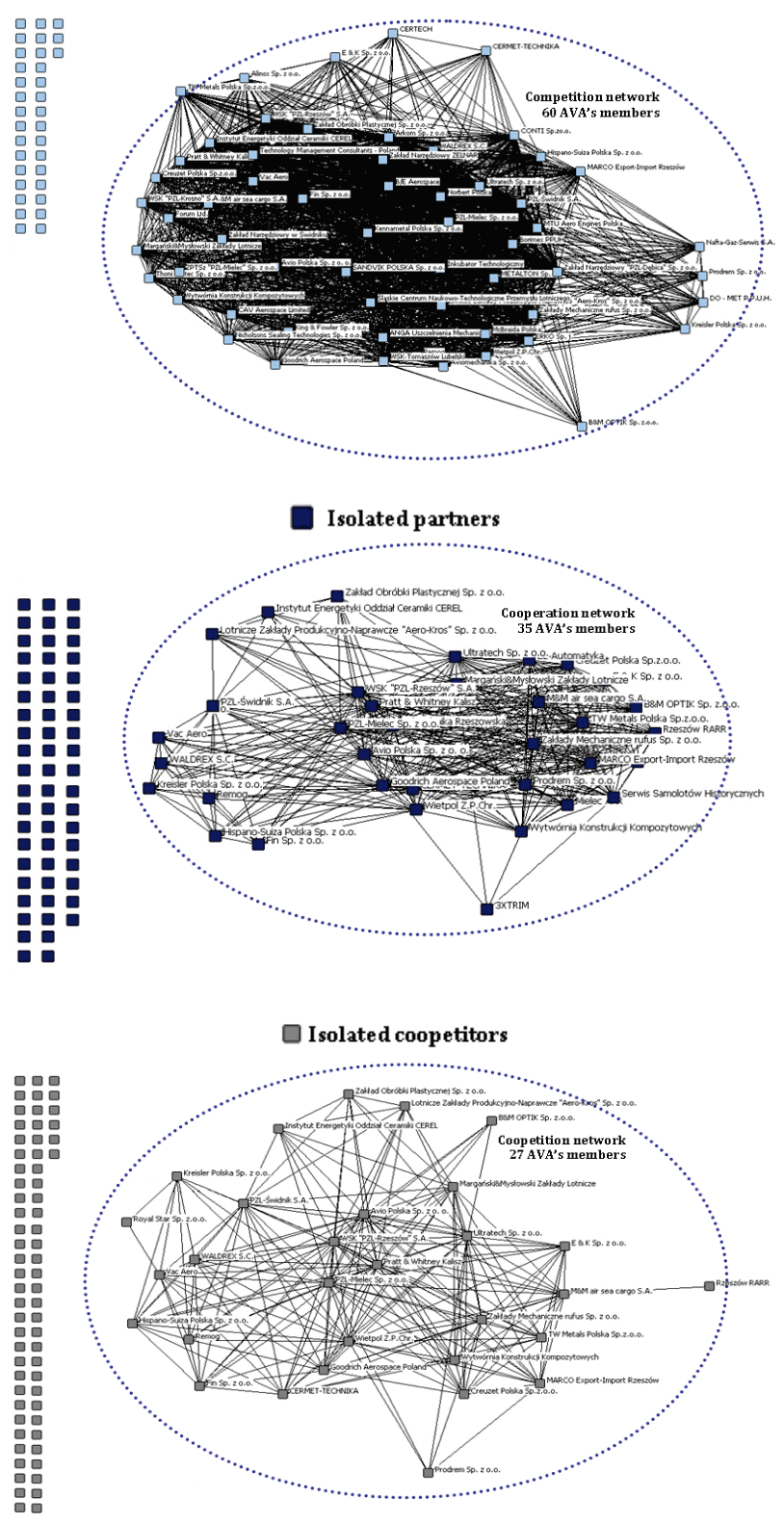

Figure 1. Competition, collaboration and coopetition networks inside Aviation Valley

Source: own work using S.P. Borgatti,, M.G. Everett, and L.C. Freeman (2002). Netdraw Network Visualization. Analytic Technologies: Harvard, MA 
First, the competition ties are represented by the overlapping business domain of the network members. The range of provided products and (or) services of nodes was identified based on information presented on the Aviation Valley's website (database of services and products provided by particular network members). In a competition network, the more overlapping the business areas, the higher the tie strength.

Second, the cooperative ties concern joint participation in industry research institutions (Polish Aeronautical Technology Platform, Air Force Institute of Technology, Institute of Aviation, Association of Polish Aviation Industry) and jointly realized research projects under the $5^{\text {th }}, 6^{\text {th }}$ and $7^{\text {th }}$ Framework Programmes of the EU. The process of identification of the projects realized with the support of Framework Programmes was based on the database provided by the Community Research and Development Information Service (http://cordis.europa.eu). Among the search criteria there were: Contract type: prime contractor or other contractors; Subject index: aerospace technology; Organization country: Poland. In general, Polish organizations participated in 164 projects and the AVA's members participated in 21 of them. In the cooperation network the ties between the two nodes represent at least one joint membership in a research project or institution and the more joint memberships and completed projects, the higher the tie strength.

To create both cooperation and competition networks, the two, separate two-mode matrices were used. In the next step they were transformed into two, separate cooperation and competition one-mode matrices consisting of ties among the AVA's members. Based on these one-mode matrices, the cooperation and competition networks structures were analyzed.

Third, the coopetition network was created as the intersection of cooperation and competition networks. In other words, only those organizations simultaneously identified as both competitors and collaborators for themselves were classified as coopetitors. Such an approach allowed us to take into consideration only ties reflecting simultaneous cooperation and competition (Bengtsson and Knock, 1999, 2000). In contrast to the cooperation and competition network, the network of coopetition was created based on a matrix filled with dummy variables $(0$ if there is not simultaneous cooperation and competition and 1 if there is) and an analysis of tie strength has not been conducted.

It should be noted that all considered ties are reciprocal, due to their naturally two-way character - when $\mathrm{A}$ is a competitor (research partner) for $\mathrm{B}$ then $\mathrm{B}$ is also a competitor (research partner) for A. It should also be added that only formal ties between particular nodes were used to create 
cooperation, competition and coopetition networks. Formal network analysis has provided information about the closest rivals (competition network), coopetitors (coopetition network) and partners (mainly cooperation network). Furthermore, structural analysis has allowed us to gain information about the network structure (e.g. the number of nodes and their importance, density and centrality of network) and relationship patterns (e.g. the number of ties, their character and strength).

Generally speaking, Aviation Valley is a more competition- than cooperation-oriented network, consisting of 93 nodes. Currently the majority of them -60 organizations $(64.52 \%)$ - are linked by competitive ties (in total 2,876 ties) while only 35 of them (37.63\%) maintain cooperative ones (in total 772ties). There are also 27 organizations (29.03\%) whose cooperative and competitive ties are overlapping - these nodes are linked by 385 coopetitive ties. It should be stated that 26 of the network members do not maintain any active (competitive, cooperative or coopetitive) links, meaning that $27.96 \%$ are completely isolated. Therefore from the network theory perspective, these organizations ought to be excluded from further analysis. However, all of them are members of the same - investigated here - industrial cluster. This means that they are linked to each other only by joint membership of the AVA and do not maintain any other relationships. Those ties were excluded from our analysis.

It was found that only $15 \%$ of competitive ties are simultaneously cooperative ones. Such a result may indicate that only a small group of competitors is willing to collaborate or meet the requirements for cooperation. There is no statistical significance of the relationships between the number of competitive (COM_degree) and cooperative (COO_degree) ties maintained by particular members of the AVA (Table 1). This means that the simultaneous establishment and maintenance of cooperative and competitive ties occur by pure chance rather than by relationships between cooperation and competition. This may suggest that the coopetition strategies adopted by the AVA's members are emerging rather than deliberate.

Table 1

The linear correlation coefficients: competition - cooperation

\begin{tabular}{l|r|r|r|r|r|r|r}
\hline \multirow{2}{*}{ Variable } & \multirow{2}{*}{ Average } & \multirow{2}{*}{$\begin{array}{c}\text { Standard } \\
\text { deviation }\end{array}$} & \multirow{2}{*}{$\mathbf{N}$} & \multicolumn{2}{|c|}{ Pearson } & \multicolumn{2}{|c|}{ Spearman } \\
\cline { 6 - 8 } & & & Correlation & $\begin{array}{l}\text { Relevance } \\
\text { (bilateral) }\end{array}$ & Coefficient & $\begin{array}{l}\text { Relevance } \\
\text { (bilateral) }\end{array}$ \\
\hline COM_degree & 30.92 & 24.853 & 93 & 0.194 & 0.062 & 0.163 & 0.119 \\
\hline COO_degree & 8.30 & 11.735 & 93 & & & \\
\hline
\end{tabular}

Source: own work, calculations were performed using SPSS Statistics 21 
This also may indicate that besides close location, institutional convergence, similar technology and knowledge, there are other important premise to establish cooperation with competitors. In other words, to link competitors by cooperative ties there are probably other (except for geographical, cognitive and institutional)factors or dimensions of proximity (Boschma 2005) required, such as social proximity strongly based on trust and interpersonal relationships.

\section{Analysis at network level}

The processes inside Aviation Valley connect different types of organizations - companies, research institutes, local and central governmental unites. However, it should be highlighted that only companies co-create a coopetition network, while all the non-economic nodes remain outside. At the same time, all types of organizations participate in competition and collaboration networks. In general, most of the interconnected organizations are SMEs. The share of large organizations in the network structure is the greatest in cases of a coopetition network (26\%). It is worth noting that almost all the large competitors ( 7 out of 9), maintain cooperative ties inside the AVA.

Two out of the three investigated networks are quite cohesive and the particular nodes are tightly connected (Table 2 ). Every coopetitior maintains approximately fourteen (out of the 26 possible) active ties through which cooperation and competition processes are run simultaneously. In the case of a competition network, every competitor has to face competition in several areas (provided products and services) with approximately 31 competitors.

Taking into consideration the number of ties and nodes it is possible to identify the network density. The densest network it is the coopetition one. It is characterized by the density of 0.548 , meaning that within the network more than $50 \%$ of the possible links are used. In other words, coopetitors use $54.8 \%$ of the communication channels for technology, information and knowledge transfer. On the other hand, this also shows that nodes are surrounded by a dense network of communication which increases the risk of unintended leakage of knowledge as the network consists of direct competitors. Furthermore, such a high level of network density may result in a lock-in effect. However, the high network closure points to easy and quick access to information. It also strengthens inter-organizational trust by facilitating sanctions that make it less risky for organizations in the network to trust one another (Burt 2001). It is quite easy to link any pair of nodes through existing ties and other nodes (connectedness at the level of 1). It is 
Table 2

Network level analysis

\begin{tabular}{|c|c|c|c|c|}
\hline $\begin{array}{l}\text { Network level } \\
\text { characteristics }\end{array}$ & Cooperation & Competition & Coopetition & Interpretation \\
\hline Nodes & 35 & 60 & 27 & Network size. \\
\hline Ties & 772 & 2876 & 385 & - \\
\hline $\begin{array}{l}\text { Members } \\
\text { Companies } \\
\text { Research } \\
\text { Institutes } \\
\text { Governmental } \\
\text { Units } \\
\end{array}$ & $\begin{array}{l}\checkmark \\
\checkmark \\
\checkmark\end{array}$ & $\begin{array}{l}\checkmark \\
\checkmark \\
\times\end{array}$ & $\begin{array}{l}\checkmark \\
x \\
x\end{array}$ & - \\
\hline $\begin{array}{l}\text { Members } \\
\text { Large } \\
\text { Medium } \\
\text { Small } \\
\text { Micro } \\
\end{array}$ & $\begin{array}{r}23 \% \\
29 \% \\
42 \% \\
6 \% \\
\end{array}$ & $\begin{array}{r}15 \% \\
40 \% \\
37 \% \\
8 \% \\
\end{array}$ & $\begin{array}{r}26 \% \\
37 \% \\
33 \% \\
4 \% \\
\end{array}$ & - \\
\hline Avg. degree & 8.301 & 30.925 & 14.667 & $\begin{array}{l}\text { The approximate amount of maintained } \\
\text { active ties by every node to other } \\
\text { network nodes. The higher degree the } \\
\text { higher connectedness with the network, } \\
\text { the better access to information and the } \\
\text { lower risk of isolation. }\end{array}$ \\
\hline Density & 0.090 & 0.336 & 0.564 & $\begin{array}{l}\text { The general level of linkage among } \\
\text { nodes in the network. The higher } \\
\text { network density the more complete the } \\
\text { network - in a complete network all ties } \\
\text { are active and all nodes are linked to } \\
\text { each other. }\end{array}$ \\
\hline Components & 2 & 2 & 2 & $\begin{array}{l}\text { The amount of sub-graphs inside the } \\
\text { network. The higher number of } \\
\text { components the more disconnected the } \\
\text { network. }\end{array}$ \\
\hline Closure & 0.837 & 0.904 & 0.722 & $\begin{array}{l}\text { The higher closure the higher } \\
\text { interconnections (nodes linked to a } \\
\text { particular node are also connected } \\
\text { between themselves). }\end{array}$ \\
\hline Avg. distance & 1.351 & 1.160 & 1.436 & $\begin{array}{l}\text { The average number of ties required to } \\
\text { connect two nodes. The higher distance } \\
\text { between nodes the weaker their access } \\
\text { to the knowledge and information flow. }\end{array}$ \\
\hline Diameter & 2 & 2 & 2 & $\begin{array}{l}\text { The longest geodesic in the network } \\
\text { and the largest nodal eccentricity. The } \\
\text { higher diameter the higher number of } \\
\text { relations in the shortest possible way } \\
\text { from one node to another. }\end{array}$ \\
\hline
\end{tabular}

Source: own work, this interpretation was developed with the use of Prell 2012; Scott, 2000; Wassermann and Faust 1997; calculations were performed using S.P. Borgatti, M.G. Everett, and L.C. Freeman (2002). Ucinet for Windows: Software for Social Network Analysis. Harvard, MA: Analytic Technologies. 
worth noting that a completely different structure describes the cooperation processes. The cooperation network is characterized by a loose system of cooperative links, which is a hallmark of innovation networks (Dhanaraj and Parkhe, 2006; Möller and Rajala, 2007; Czakon 2012). The average length of the shortest path between nodes is about 1.16 ties in a competition network, 1.35 ties in a cooperation network and 1.44 ties in a coopetition network. Regardless of the type of considered inter-organizational dynamics the diameter is equal to 2 , which means that the farthest two nodes in the network are distant at 2 ties. There are also no cut points. Therefore all three networks are well connected and stable. The separation of any node (partner, competitor or coopetitor) will not break or divide the particular network. From the managerial point of view this means that it is quite easy to ensure the network's stability. Furthermore, when we take a closer look into the density of both cooperative and competitive ties of particular nodes, we find that the majority of network members - 25 organizations - have a denser competition than the cooperation network of relationships. On the other hand, if we narrow our perspective to a coopetition network only then we will find that $93 \%$ of the linked network members have competition-dominated ties while only $7 \%$ of them have cooperation-dominated relationships (Bengston and Kock, 2000). To make this more detailed, amongst the 27 organizations which maintain cooperative and competitive ties simultaneously there are only two companies with cooperation-dominated relationships, namely Cermet Technika and B\&M Optik (see Figure 2).

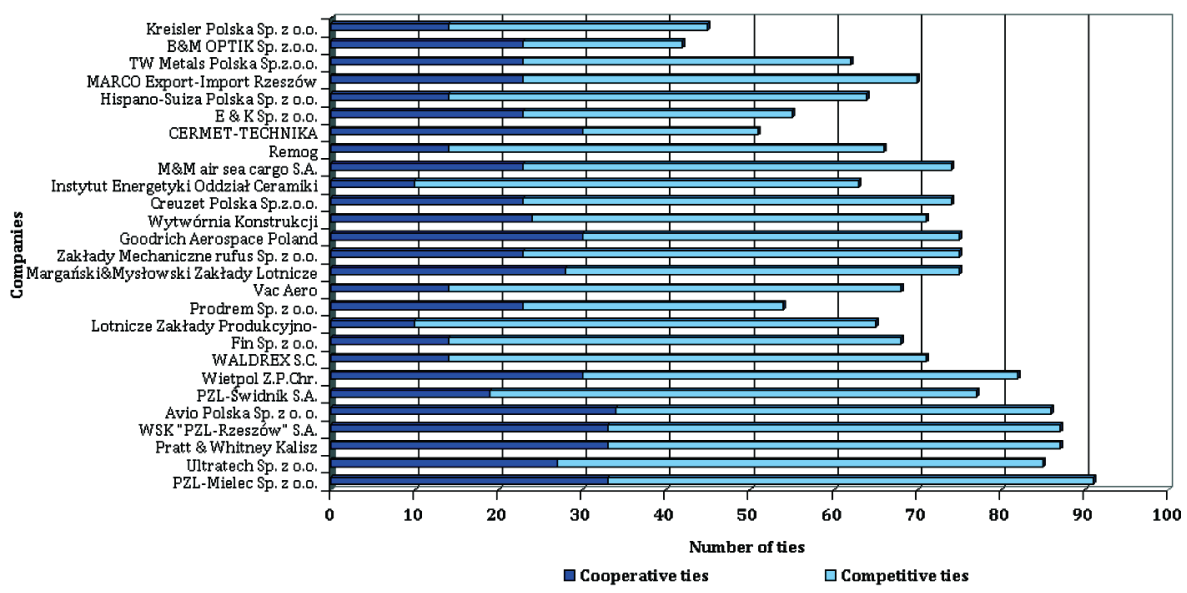

Figure 2. The distribution of the cooperative and competitive ties among coopetitors

The order of appearance represents the intensity of coopetition relationships, at the bottom of the figure are the most active coopetitors.

Source: own work 
According to this, coopetitors are more competition than cooperation oriented. Therefore network members should apply the principle of limited confidence.

Generally, all three networks are compact and cohesive. There are quite good conditions for communication, information flow and knowledge spillover, especially among coopetitors. However, when we take a closer look at the high level of cohesion and connectedness inside the coopetition network we will see that it is rather less centralized and has no single points of failure. There are no structural holes which usually control whole network outcomes and broker the general information flow.

\section{Analysis at sub-group level}

Structural analysis may be used to designate different sub-groups within the network, which is important to monitor the network stability. The analysis at macro level has shown that all the considered networks are quite well connected and cohesive. The lack of structural holes and cut points strengthens their density. At the meso level it is important to monitor if there are any sub-groups inside the network which in the case of their isolation may contribute (or cause) the network disintegration or destruction. Theoretically it is possible to distinguish sub-groups characterized by higher levels of cohesion and interconnections than a whole network, for instance k-cores (presented in Figure 3) may be used.

In the most cohesive and succinct sub-groups there are 45-cores (competition network), 23-cores (cooperation network) and 12-cores (coopetition network). Inside these sub-groups every node is linked with others by at least 45,23 or 12 ties. Such a high level of connectedness indicates that it is difficult to separate particular nodes from the networks and ensures network stability. On the other hand, it indicates that particular nodes are highly entangled in the particular networks and it can be difficult to work outside. The character and connectedness within and among the identified sub-groups support the previous results about the high level of networks' stability. It is worth noting that these sub-groups should be

perceived as an area of social capital concentration, characterized by an above-average level of trust and willingness to knowledge sharing (Broekel and Hartog, 2011), especially in cases of cooperation and coopetition networks. 

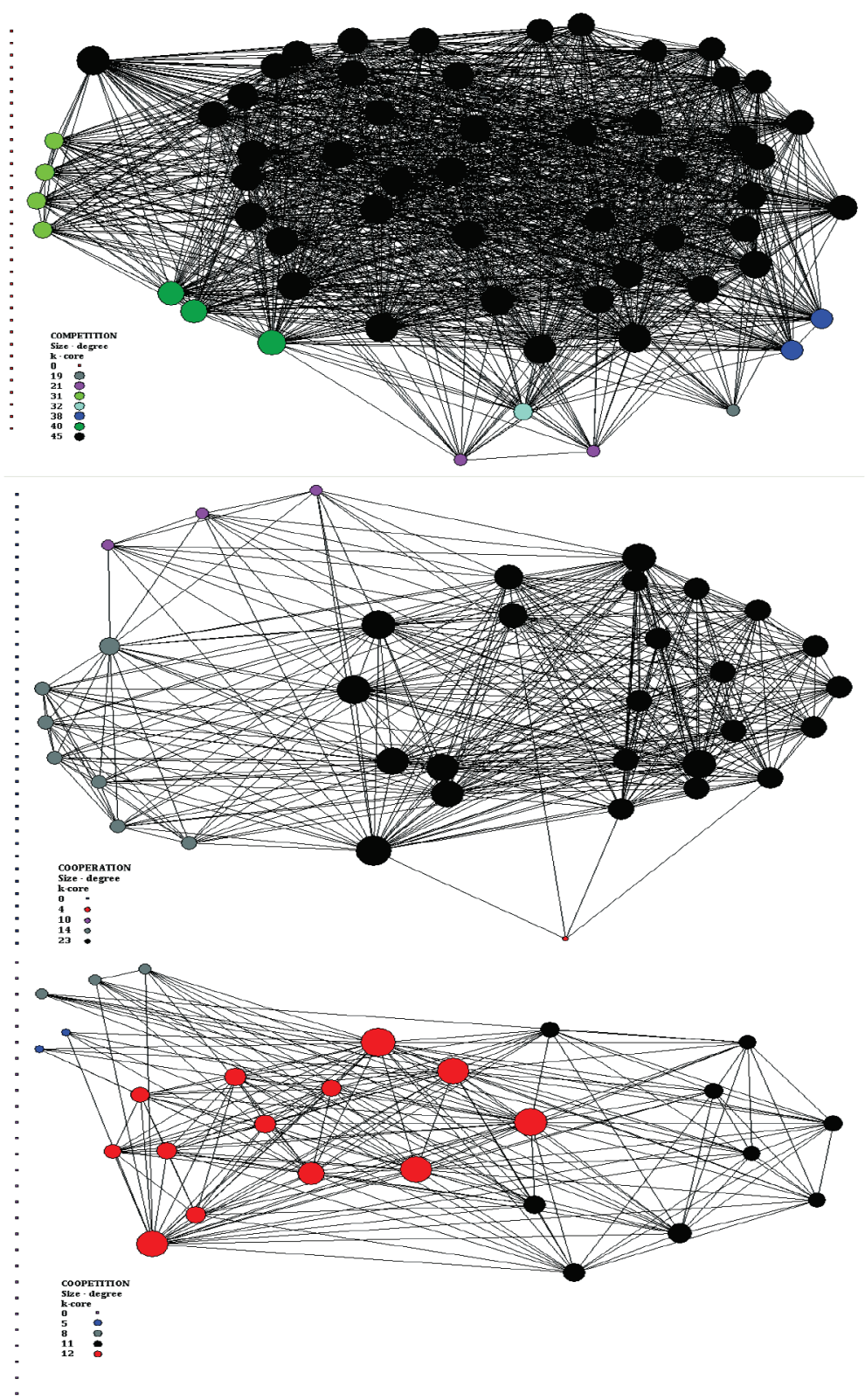

Figure 3. K-cores within competition, collaboration and coopetition networks

Source: own work using S.P. Borgatti,, M.G. Everett, and L.C. Freeman (2002). Netdraw Network Visualization. Analytic Technologies: Harvard, MA 


\section{Analysis at node level}

The above results were obtained by applying structural analysis on macro (network) and meso (sub-group) levels. Nevertheless, to get a comprehensive network picture it is important to carry out structural analysis on three levels simultaneously. The network structure consists of nodes and the links among them. The actors may vary in size, age, organizational form and business domain. From the structural point of view they also vary in their position within the network which may be considered using several different measures at the micro level of analysis - see Table 3.

Table 3

Node level analysis

\begin{tabular}{|c|c|c|c|c|c|c|}
\hline \multicolumn{3}{|c|}{$\begin{array}{l}\text { Network level } \\
\text { characteristics }\end{array}$} & Cooperation & Competition & Coopetition & Interpretation \\
\hline \multirow{8}{*}{ 疍 } & \multirow{2}{*}{ Degree } & 皿 & 34 & 19 & 26 & \multirow{2}{*}{$\begin{array}{l}\text { The number of maintainec } \\
\text { ties within the network }\end{array}$} \\
\hline & & 8 & 4 & 58 & 5 & \\
\hline & \multirow[b]{2}{*}{ Betweenness } & 由) & 36.4 & 11.9 & 31.3 & \multirow[b]{2}{*}{$\begin{array}{l}\text { The frequency o } \\
\text { appearing on the pat } \\
\text { between two others, no } \\
\text { interconnected nodes } \\
\text { Betweenness centrality is } \\
\text { related to fulfilling the rolc } \\
\text { of information broker. }\end{array}$} \\
\hline & & 8 & 0.0 & 0.0 & 0.0 & \\
\hline & \multirow[b]{2}{*}{ Closeness } & 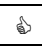 & 5428 & 3220 & 6164 & \multirow{2}{*}{$\begin{array}{l}\text { Overall distance of parti } \\
\text { cular node from all othe } \\
\text { members of the network. }\end{array}$} \\
\hline & & 8 & 8556 & 8556 & 8556 & \\
\hline & \multirow[b]{2}{*}{ Eigenvector } & $\$$ & 0.219 & 0.146 & 0.284 & \multirow{2}{*}{$\begin{array}{l}\text { The relative node evalu- } \\
\text { ation based on the number } \\
\text { of connections with other, } \\
\text { the most interconnected and } \\
\text { central nodes. }\end{array}$} \\
\hline & & 8 & 0.032 & 0.053 & 0.0 & \\
\hline \multicolumn{3}{|c|}{$\begin{array}{l}\text { The most central } \\
\text { nodes }\end{array}$} & $\begin{array}{l}\text { Avio Polska } \\
\text { WSK Rzeszów } \\
\text { Pratt\&Whitney } \\
\text { PZL Mielec } \\
\text { Politach. Rzesz. } \\
\end{array}$ & $\begin{array}{l}\text { Ultratech } \\
\text { Norbert Polska } \\
\text { PZL Świdnik } \\
\text { PZL Mielec } \\
\text { MTU Aero } \\
\end{array}$ & \begin{tabular}{|l|} 
PZL Mielec \\
WSK Rzeszów \\
Pratt\&Whitney
\end{tabular} & - \\
\hline \multicolumn{3}{|c|}{$\begin{array}{l}\text { The least central } \\
\text { nodes }\end{array}$} & $\begin{array}{l}58 \text { isolated } \\
\text { nodes }\end{array}$ & $\begin{array}{l}33 \text { isolated } \\
\text { nodes }\end{array}$ & \begin{tabular}{|l|}
66 isolated \\
nodes
\end{tabular} & - \\
\hline
\end{tabular}

Source: own work, this interpretation was developed with the use of Prell 2012; Scott, 2000; Wassermann \& Faust 1997; calculations were performed using S.P. Borgatti, M.G. Everett, and L.C. Freeman (2002). Ucinet for Windows: Software for Social Network Analysis. Harvard, MA: Analytic Technologies. 
In general, at micro level, structural analysis may be used by particular nodes to assess their positions, roles and power within the network. Based on centrality measurements (degree, closeness centrality, betweenness centrality and eigenvector centrality) it is possible to identify the most powerful and prestigious network members.

The most active and interconnected research partners which benefit from the widest access to the industrial knowledge are AvioPolska, WSK Rzeszów, Pratt and Whitney, PZL Mielec and Rzeszów University of Technology. In the case of a coopetition network, the most central positions are occupied by WSK Rzeszów, Pratt and Whitney and PZL Mielec. Central nodes within both cooperation and coopetition networks benefit from their powerful and prestigious positions. First, the most central research partners and coopetitors have the highest number of direct ties (degree) and therefore they are the most active nodes. Through this wide range of direct ties they have the widest access to network resources and obtain the greatest benefit from the network heterogeneity. Secondly, they play the role of the best information/knowledge brokers within the network (betweenness centrality) because they are on the largest number of geodesic paths between other nodes in the network. They mediate among other cooperative nodes, giving them the largest relative control over the whole cooperation network (Czakon 2012). This means that other nodes reach each other through them, which allows them to be well informed and to benefit from e.g. unintended knowledge flows. However, it should be highlighted that they are not structural holes (understood as the gaps in network structure between disconnected nodes - Burt, 1992) and the network is not exposed to the maximization of disconnections (Ahuja 2000). Thirdly, they have short and fast paths to all the other nodes within the network (closeness centrality), these organizations are among the closest nodes to all others. This allows them to go through the least number of links in order to reach every other node in the networks. That is why they have the quickest access to information and knowledge generated and transferred inside the cooperation or coopetition network. Finally, they are closest linked with the others and also the most powerful and central network nodes (eigenvector centrality). They are the most feared and respected partners and competitors for collaboration. In general they should be perceived as the best potential research partners due to the fact that they have greatest strength of influence on the whole networks and the best access to information flows.

On the contrary, in the case of the competition network, the most central nodes have to face the highest level of rivalry. Such nodes as Ultratech, Norbert Polska, PZL Świdnik, PZL Mielec and MTU Aero Engines have to 
struggle with the highest level of competition within Aviation Valley. The business activities of the most central competitors have the highest level of convergence with the business domains of other members of the aviation cluster. It is worth noting that almost all the centrality measures indicate that the most central positions in all three networks is occupied by PZL Mielec, which is the most central research partner, competitor and coopetitor.

Based on centrality measures it was possible to identify the strongest nodes (described above), and also the weakest nodes in the investigated networks. Among the weakest ones are the isolated nodes. These organizations are the furthest from the knowledge and information flows, the most vulnerable to exclusion from the network and generate the least benefit from participation in the cluster.

\section{SUMMARY AND CONCLUSIONS}

Nowadays, most organizations are embedded in inter-organizational networks (Gnyawali and Madhavan, 2001; Hoffmann et al., 2010). This growing popularity of networking may be explained by two major factors. First, the organizations strive to improve competitiveness. Second, it is a necessity imposed by the highly competitive market (Doz and Hamel, 2006). In general, the need for cooperation may be explained by such conditions as globalization, shortening life cycles of technologies and products, the increasing complexity of technologies, and deeper and faster changes in the economy. Moreover, regardless of cooperation rationale, the participation in networks provides significant benefits (Powell et al., 1996; Dyer and Singh, 1998; Lorenzoni and Lipparini, 1999; Kogut 2000). The growing popularity of networking and the increasing number of collaborative initiatives have affected the direction of research in the field of management. Basically, the networking processes, and the relationships within and between networks have recently started to attract the special attention of researchers. To be more precise, at present the mainstream of the research on networking has moved to finding the appropriate methodological approach to investigate, shape and improve networking strategies.

One of the possible as well as promising research direction is the application of structural analysis rooted in sociological social network analysis (SNA). Using social network analysis measurements for the investigation, evaluation and improvement of networks' activity and networking strategies helps in understanding the network structure and provides a lot of managerially relevant information (Klimas 2013). Structural analysis may be used to reach a broad set of information about the 
network structure and network condition, the roles and importance of its members and the networking processes among particular nodes of the network.

A case study approach was adopted to recognize the potential usefulness of structural analysis in the field of networking processes and strategies. Research on networking was intentionally based on the Polish aviation industry, namely in Aviation Valley. The sector was picked because of its high-tech nature, strong pressure to be constantly innovative and the high level of geographical concentration which encourage networking processes. The aviation industry in fact depends on inter-organizational collaboration, thereby being a perfect environment for investigating networking processes. It should be added that Aviation Valley is the biggest (it consists of 93 organizations), the most important (it covers more than $90 \%$ of the Polish aviation industry), the most respected (it participates in the European Aerospace Cluster Partnership) and the oldest (established in 2003) aviation network in Poland.

From the structural perspective, Aviation Valley is a set of heterogeneous nodes and the various ties among them. Three types of relationships (collaborative, competitive and coopetitive) were the basis for the creation of the collaboration, competition and coopetition networks. Afterwards, the application of the structural analysis methodology allowed us to identify:

- the sources of knowledge - nodes with the highest degree in a cooperation network i.e. AvioPolska, Rzeszów University of Technology, Pratt and Whitney, PZL Mielec, WSK Rzeszów - they are the best partners for collaboration in the future;

- the most important channels for knowledge transfer - nodes with the highest betweenness centrality in a cooperation network (e.g. AvioPolska, Rzeszów University of Technology, Pratt and Whitney and PZL Mielec) and coopetition network (e.g. PZL Mielec, WSK Rzeszów, Pratt and Whitney, Wietpol and AvioPolska) - are the best partners for collaboration in the future;

- the aggressive competitors - nodes with the highest degree in a competition network i.e. MTU Aero Engines, Norbert Polska, PZL Mielec, PZL Świdnik, Ultratech - should be perceived as potential rivals and their activity should be monitored against any opportunistic behaviour;

- the isolated and peripheral partners - 35\% of AVA's members are isolated from the competition network, $62 \%$ are isolated from the cooperation network and $71 \%$ are isolated from the coopetition network - 
organizations outside the cores are excluded from knowledge flows and network resources, they gain the least benefit from networking and from knowledge spillover effects.

The above results should be taken into consideration during the process of decision-making about future industrial ties and future cooperation. Moreover, based on the conducted analysis particular nodes are able to recognize their positions in existing networks and to identify possible directions for the improvement of their positions in future. Firstly, organizations remaining outside the cooperation network (e.g. Aero AT, Borimex, Fly Polska, King and Fowler) should try to establish cooperative relationships through offering $\mathrm{R} \& \mathrm{D}$ collaboration to organizations cocreating a cooperation network presented in the second graph in Figure 1. On the other hand, organizations which co-create a cooperation network but remain on its periphery(e.g. 3XTrim, Cerel, Aero-Kros), should put some effort into the creation of new and the strengthening of the existing cooperative relationships with more central nodes (like Prodrem, ZM Rufus, Creuzet Polska etc.). It is assumed that the greater the openness for cooperation, real and active participation in a cooperation network, the higher the benefits from the intensive knowledge exchange and information flows within Aviation Valley (e.g. Möller and Rajala, 2007; Perechuda 2007; Czakon 2012). Secondly, organizations creating the core of competition network presented in the first graph in Figure 1 (especially those with the highest degree at the level of 57 like MTU Aero Engines Polska, Norbert Polska, PZL-Mielec, PZL-Świdnik and Ultratech) should try to move towards the periphery and lose competitive embeddedness by leveraging their level of specialization, acquisition of strategic and desired patents, technologies or competencies. Thirdly, organizations identified as coopetitors should try to strengthen their coopetitive relationships among themselves. It is assumed that the greater prior the experience in coopetition, the lower the risk of opportunistic behaviour and the higher the trust between partners, resulting in the greater probability of coopetition success in the future (e.g. Gulati 1999; Dozand Hamel, 2006; Hoffmann et al., 2010).

Furthermore, from the Aviation Valley's standpoint, structural analysis has provided evidence of the dominance of competitive ties within the network. The above results are contradictory to the statements made by the President of the Association who emphasizes the cooperative orientation of the cluster. He always highlights that the main aim of Aviation Valley is to strengthen research cooperation, to be able to create the first Polish civil aircraft. In his opinion the sense of the cluster could be attributed to the joint research, joint laboratories and tight cooperation especially amongst SMEs 
which "are the strength of Aviation Valley". Conversely, the conducted analysis indicates that among these SMEs there is the most intensive competition. Fierce competition among SMEs causes that the largest organizations within the AVA have a wide range of choice of suppliers and subcontractors competing for contracts. On the other hand, these large organizations are characterized by the highest cooperative attitudes. Therefore, nowadays Aviation Valley can be perceived as a good environment not for SMEs, but for the biggest aviation players providing them with access to subcontractors and research partners. These market leaders appropriate the highest value generated by the cluster while the SMEs have to face strong competition. Therefore to ensure a more balanced development of Aviation Valley in future, its authorities should be focused on the greater promotion and further extension of inter-network cooperation especially among SMEs. Using the evidence that networks are loci of resources, giving access to asset flows, information flows and status flows (Gnywawali and Madhavan, 2001) the authorities of the Aviation Valley Associations should be able to convince these SMEs about the creation and strengthening of cooperative relationships.

This paper has provided evidence of the high level of Aviation Valley's stability. Excluding isolated organizations, the results do indicate that there is a low risk of inter-organizational collaboration breakdown. The multiplicity of ties, high level of interconnectedness, the lack of structural holes and cut points should be perceived as a good harbinger for the further development of Aviation Valley. Additional data gathered through semistructured interviews indicates that a high level of network cohesion occurs in response to the requirement for collaboration. This need for interorganizational collaboration might be caused by the highly innovative, globalized and hyper-competitive character of the aviation industry.

Summing up, we argue that the recognition of the network structure may be useful for improving the networking strategy from several perspectives. First, every single node may use structural analysis to assess not only its location but also the positions of any particular node within the network (structural analysis at micro level). Furthermore, using centrality measurements (degree, closeness centrality and betweenness centrality) it is possible to identify the most powerful and prestigious network members. Considering directed networks, the level of out and in-degree of particular nodes may be used for defining knowledge sources within the whole network. Moreover, the greater the difference between in-degree and outdegree, the higher the prestige of a particular node. Furthermore, the value of the eigenvector allows us the recognition of nodes which are closely linked 
with powerful and central nodes. At node level, the betweenness centrality is used as a tool for identifying the information/knowledge brokers (structural holes) within networks. In general, the measures at node level are useful to assess the power and prestige of particular coopetitors, recognize potentially the best research partners and the closest competitors, and find out which relationships should be monitored because of the high probability of knowledge leakage. Furthermore, centrality measures help to identify the network members able to acquire higher benefits from collaboration than others.

Secondly, network members may use the structural "picture" of the network to designate different sub-groups within the network (structural analysis at meso level). The existence of network components, n-cliques, $\mathrm{k}$-cores or m-slices should be monitored - there is a possibility that these sub-groups will be isolated from the network, causing the breaking of collaboration or even the disintegration of the network. The connectedness within the sub-groups is important for maintaining the appropriate level of network stability. Moreover, sub-groups inside the network are perceived as an area of social capital concentration, characterized by an above-average level of trust and willingness to share knowledge (Broekel and Hartog, 2011).

Finally, network coordinators (including network leaders, orchestrators, hub firms, strategic centres and focal firms) may use structural analysis to assess the condition and features of the whole network to improve network governance, coordination and management (structural analysis at macro level). The network scope may be evaluated based on the quantity of nodes or length of the network diameter. Moreover, such measures as density, cohesion and connectedness provide objective and significant information for evaluating network stability, assessing the maximal speed of knowledge sharing and information diffusion. The identification of a network core and periphery shows the key players which probably have the widest access to information and knowledge spillovers. Furthermore, at network level it is possible to describe the structural equivalence between the nodes understood as the similarity of pattern of their ties with all the other nodes from the network (Gnyawali and Madhavan, 2001; 6 et al., 2006). In other words, structural equivalence may be useful for identifying the closest competitors. To summarize, structural measurements at network level are helpful for managing the network and ensuring the stability of the whole network.

Structural analysis, when carried out on three levels simultaneously network, sub-groups and nodes - allows us the identification of the patterns of relationships based on the way how nodes are connected with each other. 
The results obtained may be used for improving the collaboration, competition and coopetition strategies starting with the selection of the best partners for collaboration and coopetition, through the identification of the closest rivals, ensuring network stability and coordination and ending with network management.

It should be noticed that the application of structural analysis has some limitations. First, it has a static rather than dynamic character, the data reflects the situation at one point in time which causes that the results are built on a static timeframe. However, when a particular network (or organization) reaches a decision as to the application of the structural measurements it ought to use them in the long-term as the network structure, the level of its particular measurements as well as the positions and power of particular network nodes are changing over time. Therefore future research should consider the application of more dynamic approach using for instance a Dynamic Social Network Analysis (Pattison et al., 2003). Second, in the above case only formal ties were used for building competition, cooperation and coopetition networks. However, inter-organizational relationships are shaped by both formal and informal ties (e.g. social relationships within communities of practice, communities of interest, communities of innovation, or other diverse virtual cognitive communities) which also ought to be taken into consideration. For instance in the case of Chinese guanxi, the structure of informal ties not only shapes business relationships, but is even more important than the formal network structure. Therefore we suggest that to provide a broader scope of both theoretical and practical contributions, future research should employ the data joining both the formal and informal networks of relationships.However, to the best of the authors' knowledge - despite all of these above-mentioned limitations - this paper provides significant contribution to the existing stock of knowledge and research by presenting the possible ways of using structural measurements for the networking processes.

\section{REFERENCES}

6, P., Goodwin, N., Peck, E., Freeman, T., Managing Networks of Twenty-First Century Organizations. Palgrave Macmillan, Hampshire, 2006.

Abrahamson, E., Rosenkopf, L., Social Network Effect on the Extent of Innovation Diffusion: A Computer Simulation, "Organization Science", 8(3), pp. 289-309, 1997.

Ahuja, G., Collaboration Networks, Structural Holes, and Innovation: A Longitudinal Study, “Administrative Science Quarterly", 45, pp. 425-455, 2000. 
Barney, J. B., Firm Resources and Sustained Competitive Advantage, "Journal of Management", 17(1), pp. 99-120, 1991.

Bengtsson, M., Kock, S., Cooperation and Competition in Relationships Between Competitors in Business Networks, "Journal of Business \& Industrial Marketing", 14(3), pp. 178-193, 1999.

Bengtsson, M., Kock, S., Coopetition in Business Networks-to Cooperate and Compete Simultaneously, "Industrial Marketing Management", 29, pp. 411-426, 2000.

Borgatti, S. P., Mehra, A., Brass, D. J., Labianca, G., Network Analysis in the Social Sciences, "Science", 323(5916), pp. 892-895, 2009.

Boschma, R., Proximity and Innovation: A Critical Assessment, "Regional Studies", 39(1), pp. 61-74, 2005.

Boschma, R. A., Ter Wal, A. L. J., Knowledge Networks and Innovative Performance in an Industrial District. The Case of a Footwear District in the South of Italy, "Industry and Innovation", 14(2), pp. 177-199, 2007.

Boutilier, R. G., Social Capital in Firm-Stakeholder Networks. A Corporate Role in Community Development, "JCC 26", pp. 121-134, 2007.

Broekel, T., Hartog, M., Explaining the Structure of Inter-organizational Networks Using Exponential Random Graph Models: Does Proximity Matter?, "Papers in Evolutionary Economic Geography”, 1107, 2011.

Burt, R. S., Structural Holes: The Social Structure of Competition. Harvard University Press, Cambridge 1992.

Burt, R. S., Structural Holes versus Network Closure as Social Capital [in:] Lin, N., Cook, S. K., Burt R. S. (eds.) Social Capital: Theory and Research. Aldine de Gruyter, 2001.

Cross, R., Parker, A., Prusak, L., Borgatti, S. P., Knowing What We Know: Supporting Knowledge Creation and Sharing in Social Networks, "Organizational Dynamics", 30(2), pp. 100-120, 2001.

Czakon, W., Paradygmat sieciowy w naukach o zarządzaniu, „Przegląd Organizacji”, 11, pp. 3-8, 2011.

Czakon, W., Sieci w zarzadzaniu strategicznym. WoltersKluwer Business, Warszawa, 2012.

de Laat, M., Lally, V., Lipponen, L., Simon, R. J., Investigating Patterns of Interaction in Networked Learning and Computer-supported Collaborative Learning: A Role for Social Network Analysis, “Computer-Supported Collaborative Learning”, 2(1), pp. 41-59, 2007.

Dhanaraj, C., Parkhe, A., Orchestrating Innovation Networks, "Academy of Management Review", 31(3), pp. 659-669, 2006.

Doz, L., Hamel, G., Alliance Advantage: The Art of Creating Value Through Partnering. Wydawnictwo Helion, Gliwice (Polish edition), 2006.

Dyer, J. H., Singh, H., The Relational View: Cooperative Strategy and Sources of Interorganizational Competitive Advantage, "Academy of Management Review", 24, pp. 660-679, 1998.

Eisenhardt, K. M., Graebner, M. E., Theory Building From Cases: Opportunities and Challenges, "Academy of Management Journal”, 50(1), pp. 25-32, 2007.

Gargiulo, M., Benassi, M., Trapped in Your Own Net? Network Cohesion, Structural Holes, and the Adaptation of Social Capital, "Organization Science", 11(2), pp. 183-196, 2000. 
Gnyawali, D. R., Madhavan, R., Cooperative Networks and Competitive Dynamics: A Structural Embeddedness Perspective, "Academy of Management Review”, 26(3), pp. 431-445, 2001.

Gnyawali, D. R., Park, R., Co-opetition and Technological Innovation in Small and MediumSized Enterprises: A Multilevel Conceptual Model, "Journal of Small Business Management", 47, pp. 308-330, 2009.

Granovetter, M. S., The Strength of Weak Ties, “American Journal of Sociology”, 78(6), pp. 1360-1380, 1973.

Gulati, R., Alliances and Networks, "Strategic Management Journal", 19(4), pp. 293-317, 1998.

Gulati, R., Network Location and Learning: the Influence of Network Resources and Firm Capabilities on Alliance Formation, "Strategic Management Journal”, 20(5), pp. 397-420, 1999.

Gulati, R., Managing Network Resources. Alliances, Affiliations and Other Relational Assets. Oxford University Press, 2007.

Hoffmann, W. H., Naumann, K., Speckbacher, G., The Effect of Interorganizational Trust on Make-or-Cooperate Decisions: Disentangling Opportunism-Dependent and Opportunism-Independent Effects of Trust, "European Management Review", 7, pp. 101-115, 2010.

Jarillo, J. C., On Strategic Networks, “Strategic Management Journal”, 9(1), pp. 31-41, 1988.

Jędrysik, P., Analiza sieciowa jako instrument usprawniający orkiestrację sieci, „Przegląd Organizacji”, 10, pp. 28-32, 2010.

Klimas, P., Analiza sieciowa w naukach o zarzadzaniu [in:] Czakon, W. (ed.) Podstawy metodologii badań w naukach o zarządzaniu. Wolters Kluwer, Warszawa 2013.

Klimas, P., Sieci innowacji. Implikacje bliskości organizacyjnej. Wydawnictwo Uniwersytetu Ekonomicznego w Katowicach, Katowice, 2014.

Kogut B., The Network as Knowledge: Generative Rules and the Emergence of Structure, "Strategic Management Journal", 21, pp. 405-425, 2000.

Lakshman, C., Attributional Assumptions of Organizational Schools of Thought: Classification, Evaluation and Managerially Relevant Knowledge, "European Management Review", 9, pp. 153-167, 2012.

Lee, S., Kim, M. S., Inter-technology Networks to Support Innovation Strategy: An Analysis of Korea's New Growth Engines, "Innovation: Management, Policy \& Practice", 12(1), pp. 88-104, 2010.

Liebeskind, J. P., Oliver, A. L., Zucker, L., Brewer, M., Social Networks, Learning, and Flexibility: Sourcing Scientific Knowledge in New Biotechnology Firms, "Organization Science", 7(4), pp. 428-443, 1996.

Lorenzoni, G., Lipparini, A., The Leveraging of Interfirm Relationships as a Distinctive Organizational Capability: A Longitudinal Study, "Strategic Management Journal”, 20(4), pp. 317-338, 1999.

Marin, A., Wellman, B., Social Network Analysis: An Introduction [in:] Carrington, P., Scott, J., (eds.), Handbook of Social Network Analysis. Sage, London, 2010.

Mead, S. P., Using Social Network Analysis to Visualize Project Terms, "Project Management Journal”, 32(4), pp. 32-38, 2001. 
Möller, K., Rajala, A., Rise of Strategic Nets - New Modes of Value Creation, "Industrial Marketing Management", 36, pp. 895-908, 2007.

Müller-Prothmann, T., Leveraging Knowledge Communication for Innovation. Framework, Methods and Applications of Social Network Analysis in Research and Development, "Europäische Hochschulschriften", 3189, pp. 242-243, 2006.

Nieto, M. J., Santamaría, L., Technological Collaboration: Bridging the Innovation Gap between Small and Large Firms, "Journal of Small Business Management", 48(1), pp. 44-69, 2010.

Ohly, S., Kase, R., Škerlavaj, M., Networks for Generating and for Validating Ideas: The Social Side of Creativity, "Innovation: Management, Policy, and Practice”, 12(1), pp. 41-52, 2010.

Osarenkhoe, A., A Study of Inter-firm Dynamics Between Competition and Cooperation - A Coopetition Strategy, "Database Marketing \& Customer Strategy Management", 17(3/4), pp. 201-221, 2010.

Pattison, P., Carley, K., Breiger, R., (eds.), Dynamic Social Network Modeling and Analysis: Workshop Summary and Papers, "National Academies Press" 2003.

Park, S. H., Managing an Interorganizational Network: A Framework of the Institutional Mechanism for Network Control, "Organization Studies”, 17(5), pp. 795-824, 1996.

Peng, T. J. A., Bourne, M., The Coexistence of Competition and Cooperation between Networks: Implications from Two Taiwanese Healthcare Networks, "British Journal of Management”, 20, pp. 377-400, 2009.

Powell, W. W., Koput, K. W., Smith-Doerr, L., Interorganizational Collaboration and the Locus of Innovation in Biotechnology, "Administrative Science Quarterly", 40(1), pp. 133-134, 1996.

Prahalad, C. K., Hamel, G., The Core Competence of the Corporation, "Harvard Business Review", 68(3), pp. 79-91, 1990.

Prell, Ch., Social Network Analysis. History, Theory \& Methodology. Sage, London, 2012.

Reffay, C., Chanier, T., How Social Network Analysis Can Help to Measure Cohesion in Collaborative Distance-Learning [in:] Wasson, B., Ludvigsen, S., Hoppe, U. (eds.), Designing for Change in Networked Learning Environments. Proceedings of the International Conference on Computer Support for Collaborative Learning. Kluwer Academic Publishers, Dordrecht, 2003.

Roininen, S., Westerberg, M., Network Structure and Networking Capability Among New Ventures: Tools for Competitive Advantage or a Waste of Resources?, "Frontiers of Entrepreneurship Research", 28(15) [access: http://digitalknowledge.babson.edu], 2008.

Romanowska, M., Alianse strategiczne w świetle koncepcji zasobowej [in:] Romanowska, M., Trocki, M., (eds.), Przedsiębiorstwo partnerskie. Difin, Warszawa, 2002.

Rowley, T., Behrens, D., Krackhardt, D., Redundant Governance Structures: An Analysis of Structural and Relational Embeddedness in the Steel and Semiconductor Industries, "Strategic Management Journal", 21, pp. 369-386, 2000.

Scott, J., Social Network Analysis: A Handbook (2nd Edition). Sage Publications Ltd., London, 2000.

Shuman, J. C., Twombly, J., Rottenberg, D., Collaborative Communities: Partnering for Profit in the Networked Economy. Dearborn Trade, Chicago, 2001. 
Teng, B.-S., Corporate Entrepreneurship Activities through Strategic Alliances: A ResourceBased Approach toward Competitive Advantage, "Journal of Management Studies", 44(1), pp. 119-142, 2007.

Ter Wal, A. L. J., Boschma, R. A., Applying Social Network Analysis in Economic Geography: Framing Some Key Analytic Issues, "Annual Regional Science”, 43, pp. 739$-756,2009$.

Tichy, N. M., Tushman, M. L., Fombrun, Ch., Social Network Analysis for Organizations, "The Academy of Management Review", 4(4), pp. 507-519, 1979.

Tremblay, M., Côté, J., Balkin, D. B., Explaining Sales Pay Strategy Using Agency, Transaction Cost and Resource Dependence Theories, "Journal of Management Studies", 40, pp. 1651-1682, 2003.

Tsai, W. (2002). Social Structure of "Coopetition" within a Multiunit Organization: Coordination, Competition, and Intraorganizational Knowledge Sharing, "Organization Science", 13(2), pp. 179-190.

Van de Ven, A. H., On the Nature, Formation, and Maintenance of Relations among Organizations, “Academy of Management Review”, 1(4), pp. 24-36, 1976.

Walker, G., Kogut, B., Shan, W., Social Capital, Structural Holes and the Formation of an Industry Network, "Organization Science", 8(2), pp. 109-125, 1997.

Walter, A., Auer, M., Ritter, T., The Impact of Network Capabilities and Entrepreneurial Orientation on University Spin-off Performance, "Journal of Business Venturing”, 21(4), pp. 541-567, 2006.

Wasserman, S., Faust, K., Social Network Analysis. Methods and Applications. Cambridge University Press, 1997.

Received: June 2014

Acknowledgements: We would like also to acknowledge the help of all the individuals who made important contribution to improving this paper including: Professor Wojciech Czakon who offered his comments about the structure of the paper, two anonymous reviewers of the first version of the paper submitted to the 5th Workshop on Coopetition Strategy (2012) who provided significant suggestions about the possible directions for the development of the article, and two anonymous reviewers of the last version of the paper submitted to "Argumenta Oeconomica".

Funding: The preparation of this paper was supported by a research grant from the National Science Centre under the project titled: Organizational Proximity in Innovation Networks (contract number: DEC-2011/03/N/HS4/00372) and with the financial support of the University of Economics in Katowice, Poland. 